\title{
Development and validation of a HPTLC method for analysis of Sunitinib malate
}

\author{
Monireh Hajmalek ${ }^{1,2}$, Masoumeh Goudarzi ${ }^{1}$, Solmaz Ghaffari, ${ }^{1,2,3,}$, Hossein Attar1, \\ Mehrnoosh Ghanbari Mazlaghan ${ }^{1}$
}

${ }^{I}$ Research \& Development Department, Quality Control Laboratories, Tofigh Daru Research and Engineering Company, Tehran, Iran, ${ }^{2}$ Young Researchers \& Elite Club, Pharmaceutical Sciences Branch, Islamic Azad University, Tehran, Iran, ${ }^{3}$ Pharmaceutical Sciences Research Center, Pharmaceutical Sciences Branch, Islamic Azad University, Tehran-Iran (IAUPS)

\begin{abstract}
A simple high performance thin layer chromatography (HPTLC) has been developed and validated for determination of sunitinib malate and possible impurities. The samples were applied in forms of bands on an aluminum TLC plate pre-coated with silica gel and were separated using dichloromethane: methanol: toluene: ammonia solution as the mobile phase. Sunitinib malate was thoroughly separated from impurities including E-isomer, sunitinib $\mathrm{N}$-oxide and impurity B with a retention factor (RF) of $0.35 \pm 0.02$. Quantitative analysis of sunitinib was carried out using a mobile phase consisting of dichlor omethane:methanol:ammonia solution, $\mathrm{RF}$ value was $0.53 \pm 0.02$ for $\mathrm{Z}$ isomer. Detection was performed densitometrically in absorbance mode at $430 \mathrm{~nm}$. This method was found to produce sharp, symmetrical, and well resolved peaks. Linear relationship with the coefficients of determination $>0.99$ was achieved over the concentration range of 27.34 to $437.5 \mathrm{ng} / \mathrm{spot}$. This method provides robust, replicable and accurate results with acceptable sensitivity.
\end{abstract}

Uniterms: Sunitinib malate/quantitative analysis. High Performance Thin Layer Chromatography/ method/validation. Sunitinib malate/E-Z isomer.

\section{INTRODUCTION}

Sunitinib malate, $N$-(2-diethylaminoethyl)-5[(Z)-(5-fluoro-2-oxo-1H-indol-3-ylidene)methyl]-2,4dimethyl-1 $H$-pyrrole-3-carboxamide, is an oral anticancer drug, which is marketed under the trade name Sutent ${ }^{\circledR}$ by Pfizer, Inc., New York. The chemical structure of sunitinib malate is shown in Figure 1. This drug is a novel multitargeted tyrosine kinase inhibitor with antitumor and antiangiogenic activities for the treatment of renal cell carcinoma (RCC) and imatinib-resistant gastrointestinal stromal tumor (GIST) (Kessler et al., 2007).

A very important stage in the process of production and development of pharmaceuticals is the analysis of

\footnotetext{
*Correspondence: S. Ghaffari. Quality Control Manager, Research \& Development Department. Quality Control Laboratories. Tofigh Daru Research and Engineering Company, Tehran, Iran. Phone: +982144988020\#550. Fax: +982144985056. Pharmaceutical Sciences Branch. Islamic Azad University (IAUPS), Tehran, Iran.E-mail: s.ghaffari@todaco.com; ghaffari.s@iaups.ac.ir; soligh@yahoo.com
}<smiles>CCN(CCNC(=O)c1c(C)[nH]c(C=C2C(=O)Nc3ccc(F)cc32)c1C)OC(=O)CC(O)C(=O)O</smiles>

FIGURE 1 - Chemical structure of sunitinib malate.

components present in bulk drugs and their formulations in order to ensure that pharmaceutical products are of the quality required for their intended use. Accordingly so far, a few analytical methods have been established for the determination and quantitative analysis of sunitinib malate, which are mainly based on High Performance Liquid Chromatography (HPLC) method (Rizwana, Prakash, Mohan, 2014; Sandhya et al., 2011). Furthermore, many methods mostly based on LC/MS have been presented in order to monitor drugs in biological fluids such as plasma (Oberoi, Mittapalli, Fisher, 2013; 
Etienne Grimaldi et al., 2009; Minkin et al., 2008; De Bruijin et al., 2010). However, to the best of our knowledge, there is no published analytical method for detection and quantification of sunitinib malate based on thin layer chromatography (TLC/HPTLC).

Thin layer chromatography is a chromatography technique used to separate and analyze mixtures using a thin stationary phase supported by an inert backing. From the mid-1970s, with the introduction of modern methodological and instrumental advances made in TLC (called high performance TLC), the application of this method in qualitative and quantitative analysis of pharmaceutical, environmental, toxicological, food, and agricultural samples has increasingly grown (Sherma, 2010; Sherma, 2000, 2009; Le Roux et al., 1992; Rakesh et al., 2013). This trend continued so that nowadays in some quality control laboratories quantitative HPTLC is routinely used (Ferenczi-Fodor, Renger, Veigh, 2010).

The main advantages of HPTLC are as follows: simplicity of procedure, minimal pretreatment, efficiency with small amounts of sample, parallel analysis of samples (a $20 \times 10 \mathrm{~cm}$ plate can contain up to 72 samples, which can be analyzed simultaneously and under identical conditions), multiple nondestructive methods for detection (for example visualization and scan in visible or UV light at different wavelengths), numerous options for developing solvents, low consumption of solvents, time and cost effectiveness (In fact, the expenses associated with providing solvents and maintenance are much lower in comparison with HPLC.) These advantages along with reliability, sensitivity, and reproducibility enable this method to be an important alternative to other chromatographic techniques such as HPLC. As an instance, the results of a study indicated that while the precision and accuracy of HPLC and HPTLC methods of phospholipids can be comparable, HPTLC was more cost-effective than HPLC (Renger,1999).

In recent years, numerous publications have been devoted to the application of HPTLC methods in pharmaceutical analysis (Sherma, 2010; Askal et al., 2008; Kadam, Bari, 2007; Mhaske, Dhaneshwar, 2007). For example, the following cases can be mentioned: determination of amantadine, an antiviral drug, in pharmaceutical formulations (Askal et al., 2008), simultaneous analysis of valsartan and hydrochlorothiazide, an antihypertensive drug, in tablet formulation (Kadam, Bari, 2007), determination of omeprazole, a proton pump inhibitor, in capsule form (Jha et al., 2010), simultaneous quantitation of paracetamol, diclofenac potassium, and famotidine in tablet formulation (Khatal et al., 2010), determination of imatinib (Vadera, Subramanian, Musmade, 2007) and dasatinib (Mhaske, Dhaneshwar,
2007) as anticancer medicines in pharmaceutical form.

The present study describes a simple and viable analytical method for identification and quantitative analysis of sunitinib malate in bulk drug employing HPTLC-densitometric technique. The proposed method was developed and validated based on ICH guidelines.

\section{MATERIAL AND METHODS}

\section{Material}

Sunitinib malate salt was obtained from chemistry department at TODA Research \& Engineering Company, Iran and was used without any purification. Standard of $\mathrm{E}$ and $\mathrm{Z}$ isomer mixture, sunitinib malate $\mathrm{N}$-oxide and impurity B was purchased from TLC PharmaChem Inc., Canada. HPLC-grade methanol, dichloromethane, acetic acid, toluene, and ammonium hydroxide $(25 \%)$ were purchased from Merck, Germany. All dilute solutions of ammonium hydroxide were prepared from demineralized water with a specific conductance equal to $1.2 \pm 0.1 \mu \mathrm{Scm}^{-1}$.

\section{Instrumentation}

An automatic sample applicator (Camag Linomat IV, Switzerland) equipped with a Hamilton $100-\mu \mathrm{L}$ syringe was employed for samples application on the HPTLC plate. Chromatographic separations were performed on $20 \times 20 \mathrm{~cm}$ aluminum backed plates pre-coated with $0.2 \mathrm{~mm}$ layers of silica gel and fluorescent indicator with a $254 \mathrm{~nm}$ excitation wavelength (Kieselguhr 60F-254, E. Merck, Germany). A Camag twin-trough chamber for $20 \times 20 \mathrm{~cm}$ plates, with a stainless steel lid, was used for ascending development of the plates. Densitometric scanning was performed on Camag TLC scanner II, operated with CATS3 software while the source of radiation was a tungsten lamp.

\section{HPTLC analysis}

Pre-conditioning: After selection of the chromatographic layer, plates were prewashed with methanol, and were then activated at $70{ }^{\circ} \mathrm{C}$ for $60 \mathrm{~min}$.

Sample application: By means of an automatic applicator the samples were spotted with a constant application rate of $5 \mathrm{~s} / \mu \mathrm{L}$ in the form of bands of $6 \mathrm{~mm}$ in width. The space between bands was $4 \mathrm{~mm}$. The distance from the left edge and the bottom of the plate was kept at 30 and $20 \mathrm{~mm}$ respectively.

Selection of suitable mobile phase: The following solvent mixtures were selected as candidates for the method development: dichloromethane: methanol, 
dichloromethane: methanol: acetic acid, dichloromethane: methanol: ammonia 25\%-5\%), dichloromethane: methanol: triethylamine, and dichloromethane:methan ol:toluene:ammonia. Different compositions of above mentioned solvents were tested taking into account their polarities in order to select the optimized mobile phase for separation of sunitinib malate.

Chromatographic development: The tank was saturated for $15 \mathrm{~min}$ before insertion of the spotted plate. Plates were developed with $20 \mathrm{~mL}$ of mobile phase in strict light-protected conditions. The development distance was approximately $100 \mathrm{~mm}$. The chromatography was run at $25^{\circ} \mathrm{C} \pm 3$ and at relative humidity of $33 \% \pm 3$.

Detection and scanning: After development, the plate was dried in open air for $5 \mathrm{~min}$. Densitometric scanning was then performed in the absorbance mode and at the speed of $4 \mathrm{~mm} / \mathrm{s}$, using the tungsten light source at $430 \mathrm{~nm}$ ( $\lambda \max$ for the compounds). Monochromator bandwidth was kept at $30 \mathrm{~nm}$ and the dimension of slit was set at $5 \mathrm{~mm}$ in length and $2 \mathrm{~mm}$ in width.

\section{Preparation of stock and working solutions}

A stock solution was prepared $(500 \mu \mathrm{g} / \mathrm{mL})$ by dissolving and diluting $5 \mathrm{mg}$ of sunitinib malate $(\mathrm{MM}=532.561 \mathrm{~g} / \mathrm{mol})$ to $10 \mathrm{~mL}$ with methanol in lightprotected conditions. The solution was sonicated for 15 minutes. Working solutions of sunitinib malate were prepared in amber colored glass vials by further dilution of the stock with methanol in a concentration range of 3.91 to $250 \mu \mathrm{g} / \mathrm{mL}$.

\section{Calibration curve}

The amount of $7 \mu \mathrm{l}$ of each working solutions (3.91 to $250 \mu \mathrm{g} / \mathrm{mL}$ ), equivalent to $27.3,54.6,109.3,218.7$, $291.6,437.5,875.0$ and $1750.0 \mathrm{ng}$ per spot of sunitinib malate, were applied in three replicates on the TLC plate. The spotted plates were developed and scanned as described above. Calibration curve was constructed by plotting average peak areas versus the corresponding amounts and regression equation was calculated for sunitinib malate.

\section{RESULTS AND DISCUSSION}

\section{Method Development and Optimization}

Various chromatographic conditions were investigated to attain satisfactory results of sunitinib malate qualitative and quantitative analysis. Developing the mobile phase individually on glass and aluminum TLC plate and comparing results indicated that using aluminum backing plates produces well defined spots with better resolution. Hence, in this work, aluminum sheet plates precoated with silica gel were selected as stationary phase.

In order to achieve the optimal mobile phase which enables the separation of sunitinb malate and any possible impurities, different compositions and ratios of solvents with various polarities were tested. For instance, a number of solvent systems applied in this study are listed in Table I.

The most important impurities in this study were E isomer of sunitinib, sunitinib $\mathrm{N}$-oxide $\left(\mathrm{C}_{22} \mathrm{H}_{27} \mathrm{FN}_{4} \mathrm{O}_{3}\right)$,

TABLE I - Different kinds of solvent mixtures which are tested in this study along with $\mathrm{R}_{\mathrm{F}}$ values

\begin{tabular}{lccccc}
\hline \multirow{2}{*}{ Mobile phase } & Volume ratio & \multicolumn{4}{c}{$\mathrm{R}_{\mathrm{F}}$ values } \\
\cline { 3 - 6 } & $(\mathrm{v}: \mathrm{v})$ & Z-isomer & E-isomer & N-oxide & Impurity B \\
\hline ethyl acetate: toluene: acetic acid & $5: 3: 2$ & 0 & 0 & 0 & 0 \\
dichloromethane: methanol & $9: 1$ & 0.6 & 0.56 & 0.6 & 1 \\
& $5: 1$ & 0.43 & 0.40 & 0.5 & 1 \\
& $3: 1$ & 0.32 & 0.22 & 0.30 & 1 \\
& $1: 1$ & 0.29 & 0.29 & 0.29 & 1 \\
dichloromethane: methanol:acetic acid & $3: 1: 0.05$ & 0.41 & 0.33 & 0.51 & 1 \\
dichloromethane: methanol:NH3(25\%) & $3: 1: 0.1$ & 0.37 & 0.37 & 0.39 & 1 \\
dichloromethane: methanol: NH3(8\%) & $3: 1: 0.05$ & 0.40 & 0.31 & 0.41 & 1 \\
dichloromethane: methanol:NH3(5\%) & $3: 1: 0.1$ & 0.53 & 0.42 & 0.64 & 1 \\
dichloromethane: methanol: & $3: 1.5: 0.5: 0.05$ & 0.35 & 0.25 & 0.47 & 0.94 \\
toluene:NH3(5\%) & & & & & 0.46 \\
dichloromethane: methanol: & $3: 1: 1: 0.05$ & 0.43 & 0.36 & 0.46 & \\
toluene:NH3(5\%) & & & & &
\end{tabular}


and impurity $\mathrm{B}\left(\mathrm{C}_{20} \mathrm{H}_{20} \mathrm{FN}_{3} \mathrm{O}_{2}\right)$. Due to the presence of a double bond between 2-oxindol and the pyrrole ring, sunitinib has two stereoisomeric forms: the $\mathrm{E}$ and $\mathrm{Z}$ isomers (Honeywell et al., 2010). Although $\mathrm{Z}$ isomer is the thermodynamically stable form, it can convert to $\mathrm{E}$ isomer when it is introduced into the solution exposed to light. Also, some studies have demonstrated that $\mathrm{E}$ isomer can convert to $\mathrm{Z}$ isomer when sunitinib malate was placed in the dark. Only $\mathrm{Z}$ isomer of sunitinib is a drug substance while $\mathrm{E}$ isomer is inactive and unstable. Hence, all experiments were done in lightprotected conditions. However the Z-to-E isomerism of sunitinib could not be completely avoided. The results of trials showed that among the solvents which were tested a combination of dichloromethane and methanol with volume ratio of $3: 1$ perfectly separated the two stereoisomeric forms of sunitinib malate, so that $\mathrm{E}$ isomer appears (as a small peak) before $\mathrm{Z}$ isomer (desired drug substance) and produces sharp and symmetrical peaks without tailing. However, using this solvent system led to an overlap between the peak of sunitinib $\mathrm{N}$-oxide and $\mathrm{Z}$ isomer. Hence, in another trial, ammonium hydroxide solution with different volume ratios $(25 \%$ to $5 \%)$ was added to the above system. It was found that addition of $0.1 \mathrm{ml}$ diluted ammonium hydroxide to $5 \%$ can completely separate main drug substance from $\mathrm{E}$ isomer and sunitinib $N$-oxide impurity. Under established conditions, quantitative analysis of sunitinib malate was carried out and the retention factor $\left(R_{f}\right)$ value for $\mathrm{Z}$-isomer of sunitinib was obtained, $0.53 \pm 0.02$ (Figure 2 ). Nevertheless, as the solvent system mentioned above develops, impurity B appears on the solvent front and hence could not be properly detected. After several trials, it was found that decreasing polarities of the mentioned solvent system by adding $0.5 \mathrm{~mL}$ of toluene leads to the separation of all considered components with satisfactory $\mathrm{R}_{\mathrm{f}}$ values (Figure 3). Furthermore, the results showed that the saturation of chamber with mobile phase vapors for $15 \mathrm{~min}$ at room temperature before the development of the plate improves the spot characteristic.

Also, the optimum wavelength was determined to be $430 \mathrm{~nm}$ after scanning the developed plate from 400 $\mathrm{nm}$ to $700 \mathrm{~nm}$ using the tungsten lamp.

\section{METHOD VALIDATION}

The developed method was validated by linearity, accuracy, precision, robustness, limit of detection (LOD) and limit of quantitation (LOQ) according to the ICH guidelines. These will be discussed separately in the following sections.

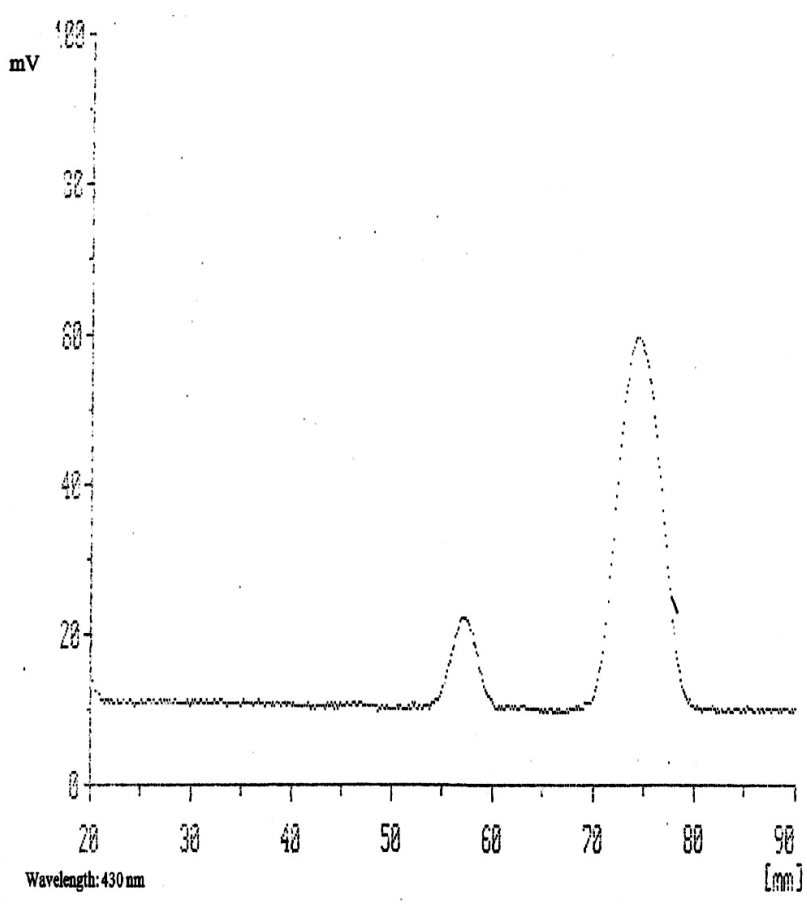

FIGURE 2 - A typical HPTLC chromatogram of sunitinib malate.

Solvent Front

Impurity $B$

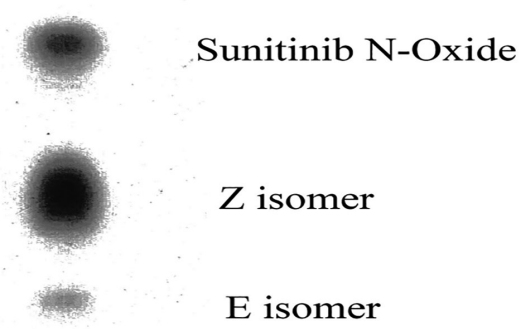

$\mathrm{E}$ isomer

\section{Baseline}

FIGURE 3 - Separation of $\mathrm{Z}$ isomer of sunitinib from related impurities using dichloromethane: methanol: toluene: $\mathrm{NH} 3(5 \%)$ with volume ratio of $3: 1.5: 0.5: 0.05$. 


\section{LINEARITY}

To evaluate linearity range, the calibration curve $(n=3)$ was plotted based on the peak area response versus sunitinib malate amount and was treated by linear least square regression (Figure 4). The results as presented in Table 2 showed a good linear relationship $\left(\mathrm{R}^{2}=0.997\right)$ over the concentration range 27.34- $437.5 \mathrm{ng}$ per spot with respect to peak area.

TABLE II - Linear regression data for the calibration curve ${ }^{a}$

\begin{tabular}{lc}
\hline Parameters & Amounts \\
\hline Linearity range & $27.34-437.50$ ng per spot \\
$\mathrm{R}^{2}$ & 0.997 \\
slope & 4.0191 \\
Intercept & 78.5292 \\
\hline
\end{tabular}

${ }^{a} n=3$

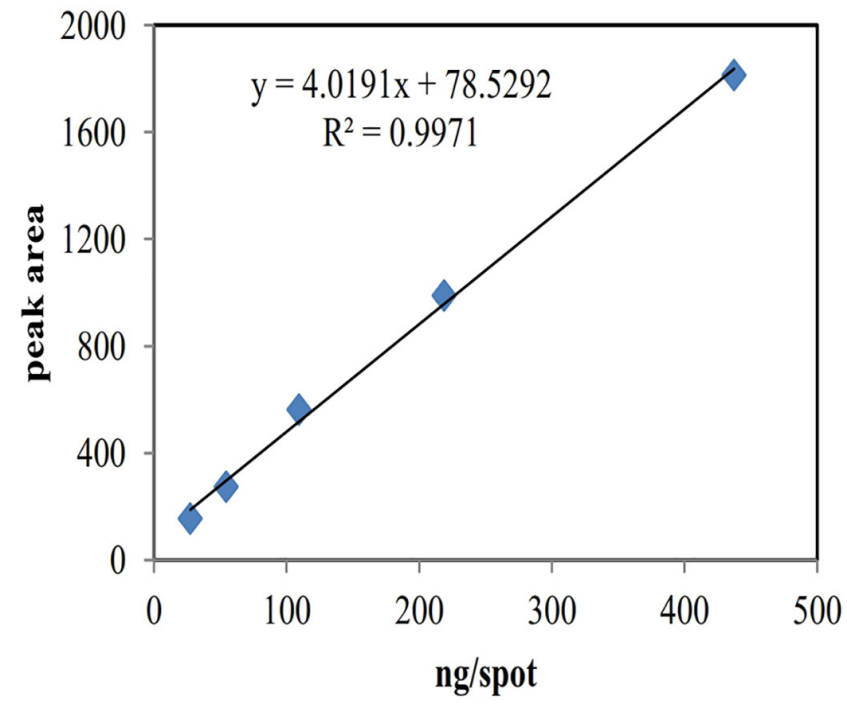

FIGURE 4 - Calibration curve for sunitinib malate.

\section{Precision}

The precision was estimated at three different concentration levels of $54.69,218.75$, and $291.67 \mathrm{ng}$ per spot to evaluate three sources of variation. At first, precision was assessed when the same spot is measured three times by densitometer. Secondly, the same solution is spotted three times, and finally overall repeatability was evaluated when the analysis was carried out in the same conditions by the same analyst during two different days. The results presented as relative standard deviation percentage $(\% \mathrm{RSD})$ depicted in Table III. The obtained
RSD values were less than $3 \%$, which confirms the good repeatability of sample application and measurement of peak area as well as acceptable intermediate precision. In TLC densitometry, RSD value in range of $1 \%-5 \%$ is acceptable (Komsta et al., 2013).

TABLE III - Precision data for sunitinib malate

\begin{tabular}{lcc}
\hline Parameters & S.D. & \%RSD \\
\hline measurement precision & 7.88 & 0.75 \\
spotting precision & 13.88 & 1.56 \\
intermediate precision & 39.38 & 2.63 \\
\hline
\end{tabular}

${ }^{a}$ Average of three concentrations 54.688, 218.750, $291.667 \mathrm{ng}$ per $\operatorname{spot}(\mathrm{n}=3)$

\section{Sensitivity}

The sensitivity of measurement was estimated as the limits of quantification (LOQ) and detection (LOD), which were expressed based on the standard deviation of the intercept and the slope of the linearity plot as described in the related ICH guideline. The LOD and LOQ are calculated by exploiting the equations $3.3 \alpha / \mathrm{b}$ and 10 $\alpha / b$, where $\alpha$ is the standard deviation of the intercept and $b$ is the slope of the corresponding calibration plot. Accordingly, the values of LOD and LOQ for sunitinib malate were found to be 23.26 and $70.50 \mathrm{ng}$ per spot respectively, as it is displayed in Table IV below.

TABLE IV - LOD and LOQ values

\begin{tabular}{lccc}
\hline Slope & $\begin{array}{c}\text { Standard } \\
\text { deviation of } \\
\text { y-intercept }\end{array}$ & $\begin{array}{c}\text { LOD } \\
\left(\text { ng spot }^{-1}\right)\end{array}$ & $\begin{array}{c}\text { LOQ } \\
\left(\text { ng spot }^{-1}\right)\end{array}$ \\
\hline 4.019 & 28.33 & 23.26 & 70.50 \\
\hline
\end{tabular}

\section{Accuracy}

The accuracy of the method was evaluated by analyzing samples of sunitinib malate with triplicate spotting at two levels of concentration, namely 72.92 and $291.67 \mathrm{ng}$ per spot. After the development of the plate, percent recoveries were calculated from the slope and intercept of the calibration plot was achieved from the linearity study. The results obtained were compared with the expected results. As it can be seen in Table IV, the percent recoveries are within the acceptable range of $90-110 \%$, which confirms the accuracy of the developed method, data for recoveries is presented below (Table V). 
TABLE V - Recovery data for sunitinib malate

\begin{tabular}{lcc}
\hline $\begin{array}{l}\text { Real } \\
\text { Concentration } \\
\left.\text { (ng spot }^{-1}\right)\end{array}$ & $\begin{array}{c}\text { Found } \\
\text { concentration } \\
\left(\text { ng spot }^{-1}\right)\end{array}$ & \% Recovery \\
\hline 72.92 & 68.20 & 93.53 \\
291.67 & 294.25 & 100.88 \\
\hline
\end{tabular}

\section{Robustness}

According to its definition, robustness is "a measure for the susceptibility of a method to small changes that might occur during routine analysis" (Komsta, Waksmundzka-Hajnos, Sherma, 2013). Hence, in this work, the effects of applying slight changes in the time intervals between chromatography and scanning, as well as the amount of mobile phase from $16 \mathrm{~mL}$ to 20 $\mathrm{mL}$, were studied. The standard deviation of peak areas was calculated for each parameter at three different concentration levels of 54.69, 218.75, $291.67 \mathrm{ng}$ per spot while \%R.S.D. was found to be less than the acceptable value of $5 \%$, which indicates the robustness of the method.

\section{CONCLUSION}

Anew HPTLC densitometric method was developed for the analysis of sunitinib malate in bulk drug and was validated in accordance with the requirements of $\mathrm{ICH}$ guidelines and proved to be repeatable, precise, accurate and robust. The procedure is simple, rapid and inexpensive in comparison with other analytical methods and, at the same time, reasonably viable in order to be suggested for the routine analysis of sunitinib malate.

\section{ACKNOWLEDGMENT}

Authors would like to thank Tofigh Daru Research and Engineering Co. for financial and technical support of this project. Authors are also grateful to Dr. Mehdi Hajmalek for English editing of the manuscript and Ali Attar for technical assistance. Authors also would like to thank Dr. Leandro Santoro Hernandes and Mrs jamie loebenberg to help us in preparing Portuguese abstract.

\section{REFERENCES}

ASKAL, H.F.; KHEDR, A.S.; DARWISH, I.A.; MAHMOUD, R.M. Quantitative thin-layer chromatographic method for determination of amantadine hydrochloride. Int. J. Biomed. Sci., v. 4, n.2, p.155-160, 2008.
DE BRUJIN, P.; LAM, M.H.; MATHIJSSEN, R.H.; WIEMER, E.A.; LOOS, W.J. Bioanalytical method for the quantification of sunitinib and its n-desethyl metabolite SU12662 in human plasma by ultra performance liquid chromatography/ tandem triple-quadrupole mass spectrometry. J. Pharm. Biomed. Anal., v.51, n.4, p.934-41, 2010.

ETIENNE GRIMALDI, M.C.; RENEE, N.; IZZEDINE, H.; MILANO,G. A routine feasible HPLC analysis for the antiangiogenic tyrosine kinase inhibitor, sunitinib, and its main metabolite, SU12662, in plasma. J. Chromatogr. B. Anal. Technol. Biomed. Life Sci., v.877, n.29, p.3757-61, 2009.

FERENCZI-FODOR, K.; RENGER, B.; VEGH, Z. The Frustrated Reviewer - Recurrent Failures in Manuscripts Describing Validation of Quantitative TLC/HPTLC Procedures for Analysis of Pharmaceuticals. J. Planar Chromatogr.-Mod. TLC., v.23, n.3, p.173-179, 2010.

HONEYWELL, R.; YARZADAH, K.; GIOVANNETI, E.; LOSEKOOT, N.; SMITH, E.F.; WALRAWEN, M. Simple and selective method for the determination of various tyrosine kinase inhibitors used in the clinical setting by liquid chromatography tandem mass spectrometry. A routine feasible HPLC analysis for the anti-angiogenic tyrosine kinase inhibitor, sunitinib, and its main metabolite, SU12662, in plasma. J. Chromatogr. B. Analyt. Technol. Biomed. Life Sci., v.878, p.1059-1068, 2010.

KHAN, S.A.; ALAM, O.; AHMAD, S. Stability-indicating high-performance thin-layer chromatographic method for quantitative determination of omeprazole in capsule dosage form. J. AOAC Int., v.93, n.3, p.787-791, 2010.

KADAM, B.R.; BARI, S.B. Quantitative analysis of valsartan and hydrochlorothiazide in tablets by high performance thin-layer chromatography with ultraviolet absorption densitometry. Acta Chromatogr., v.18, p.260-269, 2007.

KESSLER, T.; FEHRMANN, F.; BIEKER, R.; BERDEL, W.E.; MESTERS, R.M. Vascular endothelial growth factor and its receptor as drug targets in hematological malignancies. Curr. Drug Targets, v.8, n.2, p.257-263, 2007.

KHATAL, L.D.; KAMBLE, A.Y.; MAHADIH, M.V.; DHANESHWAR, S.R. Validated HPTLC method for simultaneous quantitation of paracetamol, diclofenac potassium, and famotidine in tablet formulation. J. AOAC Int., v.93, n.3, p.765-770, 2010. 
KOMSTA, L.; WAKSMUNDZKA-HAJNOS, M.; SHERMA, J. Thin layer chromatography in drug analysis. New York: CRC Press; Taylor \& Francis, 2013.

LE ROUX, A.M.; WIUM, C.A.; JOUBERT, J.R.; VAN JAARSVELD, P.P. Evaluation of a high-performance thinlayer chromatographic technique for the determination of salbutamol serum levels in clinical trials. J. Chromatogr. $B$, v.581, n.2, p.306-309, 1992.

MINKIN, P.; ZHAO, M.; CHEN, Z.; OUWERKERK, J.; GELDERBLOM, H.; BAKER, S.D. Quantification of sunitinib in human plasma by high-performance liquid chromatography-tandem mass spectrometry. J. Chromatogr. B Analyt. Technol. Biomed. Life Sci., v.874, n.1-2, p.84-88, 2008.

MHASKE, D.V.; DHANESHWAR, S.R. Stability indicating HPTLC and LC determination of dasatinib in pharmaceutical dosage form. Chromatogr., v.66, n.1, p.95-102, 2007.

OBEROI, R.K.; MITTAPALLI, R.K.; FISHER, J. Sunitinib LC-MS/MS Assay in Mouse Plasma and Brain Tissue: Application in CNS Distribution Studies. Chromatogr., v.76, n.23, p.1657-1665, 2013.

RAKESH, S.S.; DHEERAJ, H.N.; SANJAYA, U.N. HPTLC an important tool in standardization of herbal medical product: A review. J. Sci. Innov. Res., v.2, n.6, p.1086-1096, 2013.

RENGER, B. Benchmarking HPLC and HPTLC in pharmaceutical analysis. J. Planar Chromatogr.-Mod. TLC, v.12, n.1, p.58-62, 1999.
RIZWANA, I.; PRAKASH, K.V.; MOHAN, G.K. Analytical method development and validation for the estimation of sunitinib malate in bulk drug and its pharmaceutical dosage form using RP-HPLC. IAJPR., v.4, n.1, p.561-565, 2014.

SANDHYA, B.; HARIKA, V.; KASIMALLA, B.; SYED, R.; PAMMI, K. RP-HPLC method development and validation for the analysis of sunitinib in pharmaceutical dosage forms. IJSID., v.1, n.3, p.441-450, 2011.

SHERMA, J. Planar Chromatography. Anal. Chem., v.82, p.4895-4910, 2010.

SHERMA, J. Thin-layer chromatography in food and agricultural analysis. J. Chromatogr. A., v.880, n.1-2, p.129-47, 2000.

SHERMA, J. Review of advances in the thin layer chromatography of pesticides: 2006-2008. J. Environ. Sci. Health. B., v.44, p.193-203, 2009.

VADERA, N.; SUBRAMANIAM, G.; MUSMADE, P. Stabilityindicating HPTLC determination of imatinibmesylate in bulk drug and pharmaceutical dosage form. J. Pharm. Biomed. Anal., v.43, n.2, p.722-726, 2007.

Received for publication on $05^{\text {th }}$ January 2016 Accepted for publication on $13^{\text {th }}$ September 2016 
